\title{
Hypertrophic Lichen Planus
}

National Cancer Institute

\section{Source}

National Cancer Institute. Hypertrophic Lichen Planus. NCI Thesaurus. Code C34779.

A form of lichen planus that is characterized by plaques of markedly thickened skin that is often extremely pruritic and localized to the lower legs. It can result in permanent pigmentation and scarring. 